\section{Politics of science citation}

SIR-Your readers may be interested in the question whether the information sources cited by scientists change with the political alignment of the countries in which they live. If science were completely insulated from politics, one would expect the answer to be "no", but there may be practical considerations, changing patterns in education, language competence, institutional collaboration and the availabilty of publications that tend the other way.

We have carried out two studies of journal articles by scientists from Cuba and Egypt, which at various times have been aligned with the Western bloc (defined here as members of the North Atlantic Treaty Organization) and with the Eastern bloc (defined as Warsaw Pact nations).

There are difficulties in assembling representative samples of publications from these countries over more than 30 years ${ }^{1,2}$. We selected Cuban papers published in Cuban journals by the random sampling of 20 such journals and Egyptian papers published in six Egyptian journals accessible in the libraries of the University of Illinois. For articles published by scientists outside their own countries, we used an 'opportunistic' sample.

Various products of the Institute for Scientific Information (primarily the Science Citation Index and the Scisearch database) were used to identify papers published since 1967 by scientists from Cuba and Egypt; for the earlier periods, externally published Cuban and Egyptian papers were located by identifying names of scientists in biographical and directory publications and checking these in a variety of bibliography sources.

The final sample comprised 1,316 artico-authors and published between 1950 and 1983 together with 1,182 articles by Egyptian scientists between 1957 and 1983. The Cuban papers had 18,991 references and the Egyptian papers 15,222, all of which were categorized by place of publication.

For Cuba, the pre-Castro period of Western influence was defined as 1950-64 ences for citations. effects to be felt. cles with Cuban scientists as authors or as

and that of Eastern influence as 1965-83; allowing a lapse of five years after the Cuban revolution (1959) for the effects of the change to be reflected in the citations. In the case of Egypt, the period 1957-60 was defined as Western, 1961-78 as Eastern and 1979-83 as Western again, implying a lag of about three years between political re-alignment and its consequ-

At first sight, the results (see table) suggest that citation patterns are indeed influenced by political ideology: citation rates to the East increase in both countries during the period of Eastern influence. But the data contain some anomalies. The increase of Cuban citations to the East is not accompanied by a decline in citation to the West but, rather, by a decline in the citations of Cuba's own literature and, to a lesser extent, that of other Latin American countries. In Egypt, citation to the West does decline as citation to the East increases, but this trend continues even in 1979-83, categorized as a period of Western influence, suggesting that it may take longer than three years for significant

Naturally it is possible that the rate at which Cuban and Egyptian scientists cite Eastern sources does not differ significantly from the rate at which Eastern sources are cited by other non-Eastern authors. We are not aware of studies that have determined the rate at which Warsaw Pact nations as a group are cited although Nalimov and Mul'chenko ${ }^{3}$ reported in 1969 that the rate of citation of Soviet authors in the journals of other countries was in the range $3-4$ per cent and never more than 5.5 per cent, suggesting that the Cuban and Egyptian rates of citing Eastern bloc material do not differ significantly from those of other countries outside the Warsaw Pact.

Our data alone show that it is only when Cuban authors collaborate with Eastern authors or publish in Eastern journals that they cite Eastern sources more than expected. Of 14,693 references in papers by Cubans alone, only 641 are to Eastern sources ( 4.4 per cent) whereas, among 3,256 references from papers jointly by

Place of publication of sources cited by

Cuban and Egyptian scientists

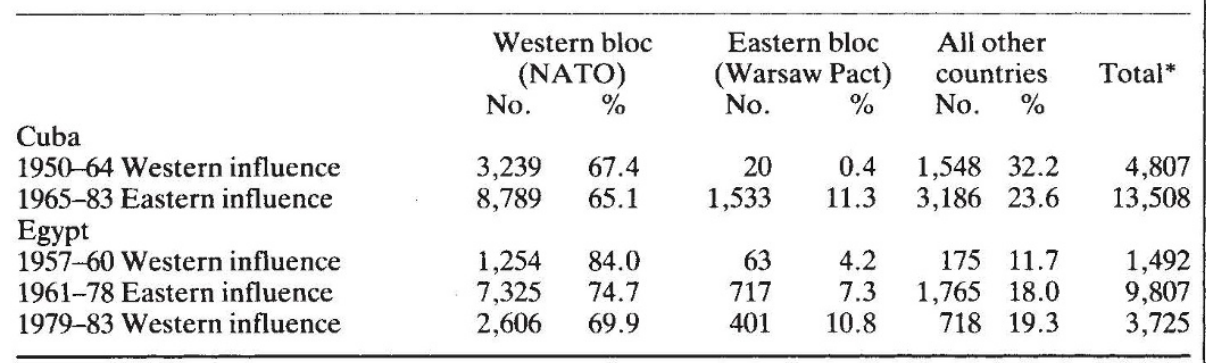

*Citations judged 'unidentifiable' by country are excluded.
Cuban and Eastern scientists, 889 (27.3 per cent) are to Eastern sources. The influence is even stronger in the reverse direction - when a Cuban collaborates with a Western author, references to the East drop to little more than 1 per cent, while references to the West increase to 80 per cent. (This is based on the 42 papers 709 references - we could locate involving collaboration between Cuban and Western scientists.)

When a Cuban publishes in an Eastern journal, 20.1 per cent $(764 / 3,792)$ of the references are to the East compared with only 4.9 per cent $(202 / 4,94)$ when publishing in a Western journal. A similar pattern was found for Egyptian authors, but the numbers involved are too small to be significant: only five papers were found in which an Egyptian collaborated with an Eastern author.

In short, we were unable to confirm that a change in the political alignment of a country leads to an overall change in the source of bibliographic citations of its scientists, but that there is a significant effect when such a one publishes in one of its journals or collaborates with one of its scientists.

F.W. LANCASTER AbDus Satar Maria A. Porta

Graduate School of Library and Information Science,

University of Illinois,

Urbana, Illinois 61801, USA

1. Lancaster, F.W. et al. Scientometrics, (in the press.)

2. Sattar, A. thesis, Univ. Illinois, Urbana, (1984).

3. Nalimov, V.V. \& Mul'chenko, Z.M. Naukometria: izuche nie razvitia nauki kak informatsionnogo protsessa, (Nauka, Moscow, 1969).

\section{Cerebral matters}

\section{SIR-}

Dear Sutherland, your erring golf swing vector $^{1}$

Needs a $30 \mathrm{~ms}$ phase-lead precorrector

From Purkinjes lookaheading,

Time derivatives embedding

In the matrix of your tensor cerebellar.

Assuming that you have a perfect program Of covariant intention in your engram,

Contravariant execution

Gets covariant restitution

By the Taylor series in your cerebellum.

If you're troubled by your left/right situation

During bottle, glass, and keyboard contemplation ${ }^{2}$

Just remember the old Tensor

When you program an extensor.

Pellionisz and Llinàs will bring salvation $T^{\alpha \beta \cdots}=0$

ERPB Laboratory,

(Hilton Stowell)

120 Nature Creek SW,

Milledgeville,

Georgia 31061, USA

1. Sutherland, S. Nature 323, 486 (1986)

2. Sutherland, S. Nature 322, 415 (1986) 